Cytogenet Genome Res 1983;35:80

\title{
ISCN (1981)
}

A number of minor discrepancies in ISCN (1981) have been drawn to our attention:

1. Bands 3pll.2, 6ql1.2, 9pll.2, 1lpl1.12, and

Xqll.2 have all been drawn as if they emerged from

the adjacent band 12 instead of from the centromeric

region, band 11. Unless this is causing problems, and

we know of none, we suggest that nothing be done

about this and that the band numbers be left as they

are at present.

The lines designating the major regions of each chromosome on the 400-band diagram may be confusing. They are relics of the original Paris diagram and were left for comparison. They will be removed at the next printing of this diagram.

Band 12q23 increases in width between the 400-

1 Birth Defects: Original Article Series, Vol. 17, No. 5 (March of Dimes Birth Defects

Foundation, White Plains, N.Y. 1981); also in Cytogenet. Cell Genet. 31: 1-32 (1981).

and the 550-band diagrams. This is a simple drawing error and will be corrected at the next printing.

4. There is a region designation error in chromosome 21 . The long arm should show region 1 and region 2. The band numbers are, however, correct. Similarly, on chromosome 9 the short arm should show regions 1 and 2, but again the band numbers are correct.

Note that though we are drawing attention to these points, no changes in band numbering are necessary, and all of these errors will be corrected at a later point.

D. G. Harnden Chairman

Standing Committee on Human Chromosome Nomenclature 